\title{
Experimental Investigation of Intake Diesel Aerosol Fuel Homogeneous Charge Compression Ignition (HCCI) Engine Combustion and Emissions*
}

\author{
Medhat Elkelawy \\ Department of Mechanical Power Engineering, Tanta University, Tanta, Egypt \\ Email: medhatelkelawy@f-eng.tanta.edu.eg
}

Received 26 September 2014; revised 25 October 2014; accepted 15 November 2014

Copyright (C) 2014 by author and Scientific Research Publishing Inc.

This work is licensed under the Creative Commons Attribution International License (CC BY).

http://creativecommons.org/licenses/by/4.0/

(c) (i) Open Access

\begin{abstract}
External mixture formation (PFI) of a diesel fuel aerosol has employed to investigate the diesel HCCI engine combustion and emissions characteristics. The key to the external mixture formation with diesel fuel is the proper fuel/air mixture preparation. A proposed intake diesel fuel aerosol system mainly consists of a small chamber, in which the diesel fuel is fully vaporized by means of fuel cavitation inside the diesel injector nozzle. Nozzle cavitation is mainly affected by the injection pressure and the fuel system temperature. Results obtained reveal that the proposed method determines the possibility of producing a complete homogeneous fuel/air mixture, which can be applied to the diesel HCCI engine. With this method, the combustion and emission behavior were entirely optimized and the engine is capable of running in HCCI combustion mode with nearly ideal mixture preparation. In the present investigation, a methodology for the HCCI combustion mode of the diesel aerosol/air mixtures based on the fuel cavitation inside the injector nozzle parameters (such as the injection pressure and the fuel system temperature where fuel premixed ratio, $\mathrm{NO}_{x}, \mathrm{CO}, \mathrm{CO}_{2}$, and $\mathrm{HC}$ emissions) have analyzed. Based on the engine performance and emissions characteristics the fuel injection pressure and the fuel system temperature have optimized to produce a suitable fuel premixed ratio and the perfect fuel/air mixture homogeneity at different engine operating conditions. The optimal injection pressure ranges between 150 - 200 bars, while the fuel system temperature lies within $175^{\circ} \mathrm{C}-200^{\circ} \mathrm{C}$. Loops of exhaust gas recirculation (EGR) are used to extend the engine load by controlling the combustion phasing.
\end{abstract}

\section{Keywords}

HCCI, Cavitation, External Mixture Formation, Diesel Injector Nozzle, EGR

\footnotetext{
"Zero emission Diesel HCCI engine.

How to cite this paper: Elkelawy, M. (2014) Experimental Investigation of Intake Diesel Aerosol Fuel Homogeneous Charge Compression Ignition ( $\mathrm{HCCl}$ ) Engine Combustion and Emissions. Energy and Power Engineering, 6, 513-526. 


\section{Introduction}

Homogeneous charge compression ignition (HCCI) technology offers great potential benefits on low $\mathrm{NO}_{\mathrm{x}}$ and particular matter (PM) emissions and high thermal efficiency. However, it does have it is unique challenge [1][4], particularly the homogenization of fuel, air, and recycled burnt gases prior to ignition, control of ignition and combustion timing, heat release rates, it is a narrow operating window, and high HC and CO emissions. From HCCI engine principal it is important to realize mixture formation and the avoidance of fuel-wall interactions to achieve high fuel efficiency, reduce HC and PM emissions, and prevent oil dilution [5]. Regarding the mixture formation and homogenization of fuel and air, two main categories, namely the external and the internal mixture formation can be distinguished.

External mixture formation is the simplest way of achieving a homogeneous in-cylinder mixture [6] [7]. This method is also known as port injection or fumigation. The turbulence created by the intake flow supports further homogenization. Because the air-fuel mixture is exposed to the whole time, temperature and pressure development, the port injection would belong to the early homogenization concepts [8]. A drawback of this strategy is that injection timing cannot be used to influence the start of ignition. Heavy fuels with low volatility results in poor evaporation, increased wall impingement increased of HC and CO emissions, and increase fuel consumption and fuel dilution [9]. However, this kind of the fuel injection is mainly attractive for gaseous and liquid fuels with high volatility.

In the case of internal mixture formation, the fuel is directly injected into the cylinder [7]. There are two strategies used for this method, i.e., early and late injection timing [4]. Early injection is mostly used for HCCI heavy fuel applications, in which a long ignition delay with low temperatures homogenizes the air-fuel mixture [10]. A significant part or even the whole amount of the fuel is injected before top dead center. In the case of heavy fuel injection, poor fuel volatility and low air density inside the cylinder may result in considerable wall wetting. For those cases, the new and highly flexible injection systems should be designed, which are used to make adaptation to the variation of combustion-chamber geometry as well as in-cylinder pressure and temperature during the injection.

Some researchers have already spent much effort on developing low penetration injectors and minimizing wall impingement [4] [11]. A suitable injection system must have a high degree of flexibility in order to allow adaptation of the injection strategy, according to the varying boundary conditions during injection [12] [13]. High-pressure injection designed with a large number of small nozzle holes is generally used in order to increase spray disintegration, and to include the complete cylinder charge in the mixture formation process while avoiding wall film formation. A further adaptation of the spray penetration can be realized by splitting the injection event into several pulses with different durations [14]. In-cylinder injection HCCI engines, the short pulse duration leads to less momentum of the liquid fuel resulting in reduced penetration. The low gas density at the start of injection requires short pulses with reduced injection velocities and relatively long time intervals between the pulses [15] [16]. As the piston moves up, charge density and temperature in the cylinder increase and penetration is reduced. The pulse durations can be prolonged, while the time intervals between subsequent pulses are shortened. At the end of the pulsed injection the distance between nozzle and piston reduces significantly and the mass injected per pulse must be reduced again in order to prevent fuel deposition on the piston [17] [18].

The recent trend for all published diesel HCCI research involves mixture preparation using the ideal conditions of HCCI combustion regimes, referred to as external mixture formation [19]. By introducing the fuel externally to the combustion chamber one can use the turbulence generated by the intake process to create a homogeneous charge regardless of engine conditions. This eliminates the need of fuel system changes, which are necessary for the internal mixture formation method. In this method, the combustion system remains fully optimized while running in HCCI combustion mode with nearly ideal mixture preparation.

Present experimental investigation is aimed to develop diesel fuel cavitation methodology in the diesel injector nozzle for preparing a fully homogeneous mixture of diesel and air. This research explores the fuel mixture preparation as well as the combustion and emission characteristics of HCCI using an external mixing device "diesel vaporizer chamber", which requires less engine fuel system modifications in the present DI engine in order to convert it into HCCI engine. Diesel vapor produced by this device also contains very small diesel droplets in the form of diesel-like aerosol fuel, which will easily mix with air to form either fully or partly homogeneous mixture. Due to the adequate mixing in the vaporization chamber, formation of mixture of air and partly vaporized fuel aerosol takes place. Various experiments were performed to investigate HCCI combustion using different EGR conditions and engine loads. 


\section{Engine and Experimental Setup}

In the present study, experimental activities have conducted in a heavy-duty commercial single-cylinder diesel engine to investigate the basic performance characteristics of diesel HCCI engines combustion and emissions. The experimental setup facilities will specifically address the operating parameters of the diesel HCCI engines such as the control of ignition timing, heat release rate, emissions over a wide range of loads, speeds, different percentage of EGR rate, different port fuel injection pressures, and temperatures of both of fuel and charged air. Moreover, the test engine was adjusted in our work to run in HCCI mode over a wide range of operating conditions to analyze the engine performance and emissions. This engine was equipped to handle intake heating and fuel additives in addition to the possibility of changing the engine loads at fixed speed and vice versa.

Test engine used in this study was naturally aspirated, four-stroke, and water-cooled. Fuel/air homogenous mixture was formed during suction and compression strokes, in which the fuel supply mode was changed from the direct fuel injection to port fuel supply. Table 1 gives the specifications of the engine and Figure 1 illustrates the schematic diagram of the engine experimental setup. The in-cylinder gas pressure was measured with a Kistlerpiezo-electric pressure transducer installed in the cylinder head, and the pressure transducer was connected with a commercial data acquisition card through a Kistler charge amplifier. In-cylinder gas pressure is then correlated to crankshaft angular position using an electro-magnetic sensor mounted on the engine crankshaft. Four thermocouples were used to measure the temperature of intake air, exhaust gas, coolant water, and lubricating oil. A further thermocouple was operated by a feedback control system to adjust the intake air and fuel system temperature. The exhaust emissions concentrations such as $\mathrm{NO}_{\mathrm{x}}, \mathrm{CO}, \mathrm{UHC}$, and $\mathrm{CO}_{2}$ were measured with NHA-500 exhaust gas analyzer which has an accessory of lambda sensor for the measurement of the excess air coefficient $(\lambda)$. The engine speed and load have controlled by an eddy current dynamometer. Before the intake manifold, a large stable surge tank was equipped with electric heater operating according to a feedback system being used to control the air charge temperature.

\section{Table 1.Test Engine specification.}

$\begin{array}{cc}\text { Bore } \times \text { Stroke/Piston Shape } & 130 \mathrm{~mm} \times 120 \mathrm{~mm} / \omega \mathrm{Shape} \\ \text { Displacement } & 1.592 \mathrm{~L} \\ \text { Connecting Rod Length/Crank Radius Ratio } & 3.742 \\ \text { Compression Ratio } & 15.1 \\ \text { Fuel Supply Mode } & 12^{\circ} \mathrm{BTDC}^{\circ} \mathrm{B}^{\circ} \mathrm{ABDC} \\ \text { Intake Valve Open/ Intake Valve Close } & 55^{\circ} \mathrm{BBDC} / 17^{\circ} \mathrm{ATDC} \\ \text { Exhaust Valve Open/ Exhaust Valve Close } & 20.22 \mathrm{KW} \text { at } 2200 \mathrm{RPM} \\ \text { Max. Power } & \end{array}$

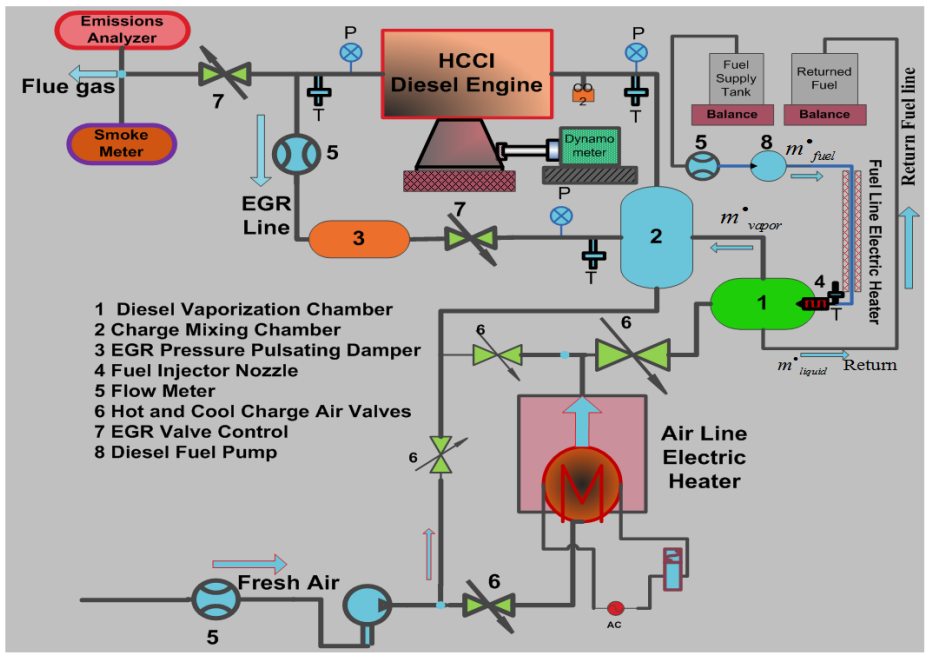

Figure 1. Schematic diagrams of the engine experimental devices. 
Homogeneous charge preparation is the most important role in achieving diesel HCCI combustion. Low volatility of diesel is the main hurdle in forming a homogeneous mixture of fuel and air, especially when injected inside the engine manifold. In the present investigation, a diesel vaporization chamber is built up for this purpose. The construction of the diesel vaporization chamber is shown in Figure 1 (part 1). The diesel vaporization chamber has two inputs and two outputs streams. The input streams are assembled for the air and diesel fuel lines, in which both quantities can be controlled and measured. The fuel and air lines ware facilitated with controllable heaters to adjust the fuel system temperature. The surfaces of the whole fuel system are thermally insulated to fix the temperature for all the system operating conditions. Fuel injector sprays the pressurized and heated fuel into the heated air inside the diesel vaporization chamber. The diesel fuel is fully vaporized by means of fuel cavitation inside the diesel injector nozzle. Nozzle cavitation is mainly affected by injection pressure and the fuel system temperature. Hot air supplied to the vaporization chamber is mixed with the diesel vapor homogeneously. This mixture is mixed with the EGR and fresh air and supplied to engine cylinder through the charge mixing chamber (part 2 in Figure 1) located in the inlet manifold.

A part of the exhaust gas is cooled and recirculated back into the combustion chamber to control the combustion phasing and extend the engine loads. The use of EGR reduces the in-cylinder maximum temperature and thereby reducing $\mathrm{NO}_{\mathrm{x}}$ emissions significantly. The exhaust gas from the engine cylinder is, however, highly pulsating in nature and thus preventing the accurate flow measurement. Therefore, a damper is inserted in the circuit to reduce the exhaust gas pulsations. A flow manometer, mounted downstream of the damper, is used to measure the flow rate of EGR across a calibrated digital reader.

The fuel employed was commercial diesel fuel with characteristics shown in Table 2. The fuel is supplied with a set of high pressure pump along with a pre-calibrated flow meters and high accuracy digital balance $( \pm 0.001$ gram absolute error). The mass flow rate of air was measured with a high accuracy digital flow meter. The atmospheric temperature in the engine test lab is usually maintained constant at $27^{\circ} \mathrm{C}$. The intake air temperature was automatically controlled using an electric intake air heater. The coolant temperature is a very important parameter that needs to be controlled during HCCI experiments. For this purpose, the coolant water was kept constant at $85^{\circ} \mathrm{C}$ during our experimental activities.

\subsection{Test-Rig Assembly, Calibration}

It is widely known that, the calibration process is a comparison between measurements which known in magnitude or correctness made with a certain device and another measurement made in a similar way as possible with a second device. Relatively, the error locates in the results must be within a certain range, which makes the results obtained reliable. Herein, comparing the measured values from the different flow meters of our test rig with the calculated values from the exhaust gas analyzer data will introduce the type of error presented. Generally, measurements have two types of errors, systematic error and the random error. Random errors are not accepted in our measurement applications, it is caused by inherently unpredictable fluctuations in the readings of a measurement apparatus or in the experimenter's interpretation of the instrumental reading. Also, systematic errors are biases in measurement where the mean of many separate measurements differs significantly from the actual value of the measured attribute.

In the following we will implement a new method for checking the device reliability for our test-rig assembly. We will calculate the air/fuel ration as a function of the exhaust gas percentages, and compare those results with the measured air/fuel ratio at the same conditions. The calculated air/fuel ratio is called spindt AFR [20]. The spindt AFR calculation method used to deduce the operating air-fuel ratio of the fuel flow rate, fuel characteristics, and emissions was introduced by Spindt for conventional fuels [21] [22].

Figure 2 represents the comparison between the calculated and the measured air/fuel ration at different engine loads and fixed engine speed of 1200 RPM with $298 \mathrm{~K}$ fuel system temperature. It is clear from Figure 2 that, for the engine operation layout when increasing the engine loads from 0 to $20 \mathrm{HP}$ at the same engine speed the both calculated and the measured air/fuel ratio decreased with increasing the load. Comparing the results shown we can conclude that, our measured acquired results from the flow meters as well as the emissions analyzer located in an acceptable tolerance range of results fitting analysis. From the shown figure it is clear that, both of the curves at different conditions show a responsible agreement in the increasing and the decreasing trend of both air/fuel ratio. We can also conclude that, the emission analyzer results of the components of the exhaust are reliable enough for our experimental work accuracy at different conditions and different measurement techniques. 
Table 2. Specifications of test fuel.

\begin{tabular}{cc}
\hline Cetane Number & 54 \\
Density & $0.813 \mathrm{~g} / \mathrm{cm}^{3}$ \\
Vapor Pressure & $40 \mathrm{~mm} \mathrm{Hg}$ \\
Surface Tension & $0.02012 \mathrm{~N} / \mathrm{m}$ \\
Dynamic Viscosity & $3.87 \times 10-4 \mathrm{~Pa} \cdot \mathrm{S}$ \\
Boiling Temperature & $280^{\circ} \mathrm{C}(95 \%)$ \\
(A/F) Stoich. & 14.5 \\
\hline
\end{tabular}

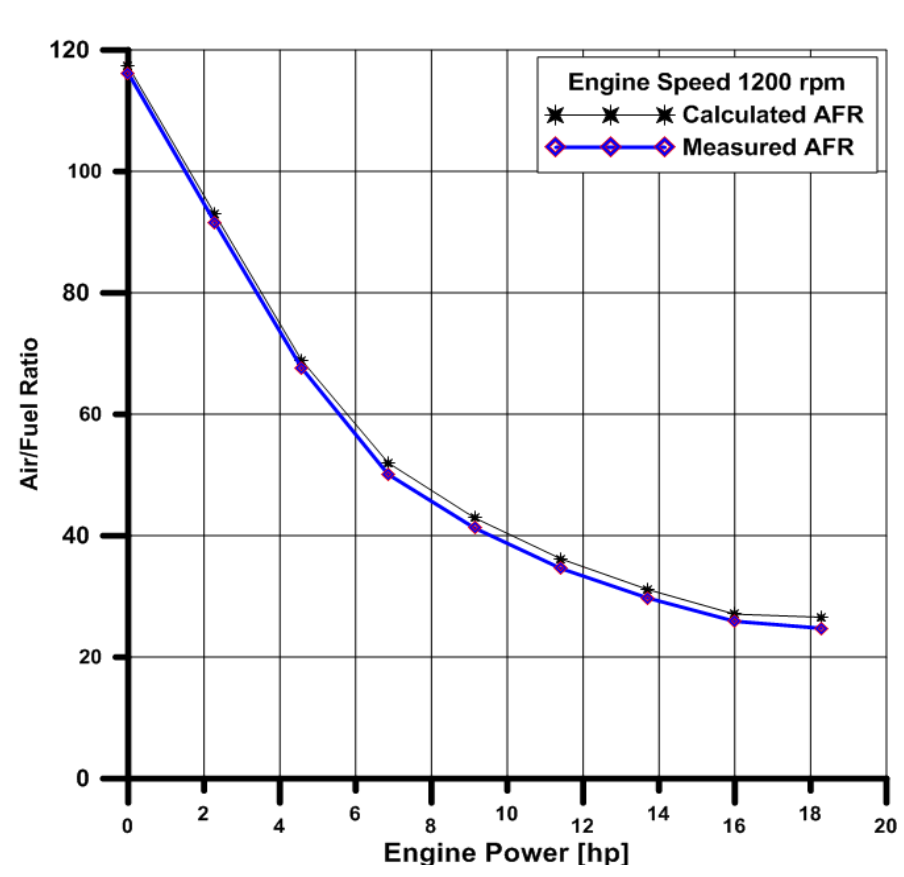

Figure 2. Comparison between calculated and measured Air/Fuel ratio at different engine load, engine speeds 1200 RPM.

\subsection{Study of the Fuel Mixture Preparation}

Homogeneous charge preparation is the first challenge for the application of the HCCI combustion mode. For port fuel injection (PFI), the injection pressure $\left(P_{i n j}\right)$, injection temperature $\left(T_{i n j}\right)$, and the physical properties of the fuel play important roles in governing mixture formation characteristics. In this experiment, diesel fuel aerosol was produced inside the injector nozzle due to the occurrence of cavitaion inside the diesel injector nozzle [23] [24]. The injected diesel into a vaporization chamber remains at a temperature equal the fuel line temperature (fuel system temperature). However, inside the fuel vaporization chamber a part of the injected liquid diesel is converted into a diesel vapor then entering the engine, the rest of the fuel is returned back to the tank in liquid state. But the returning liquid fuel may not vaporize completely in every cycle, because of not reaching the vaporization point of the diesel in some conditions. So, the amount of the fuel sucked into the cylinder could not be directly calculated from the fuel consumption, according to electronic balance shown in Figure 1 .

In order to estimate the vaporization rate of the injected diesel fuel, the fuel premixed ratio (FPR), in this work, is defined using the Equations 1 and 2 as the following:

$$
\mathrm{FPR}=\dot{m}_{\text {vapor }} / \dot{m}_{\text {fuel }}
$$

Where, $\dot{m}_{\text {vapor }}$ is the diesel fuel consumption in the form of aerosol fuel, which can be calculated from the electronic balances reading of $\dot{m}_{\text {fuel }}$ and the $\dot{m}_{\text {liquid }}$ return as can be seen in Figure 1.

$$
\dot{m}_{\text {vapor }}=\dot{m}_{\text {fuel }}-\dot{m}_{\text {liquid }} \text { Return }
$$


To study the effect of injection pressure and temperate on the production of diesel vapor from the vaporization chamber and its effect on the fuel premixed ratio (FPR) the engine speed is fixed at 1200 RPM and the fuel system temperature and injection pressure $\left(T_{i n j}\right.$ and $\left.P_{i n j}\right)$ have been investigated in the range of 25 to $225^{\circ} \mathrm{C}$, and 75 to 250 bars, respectively. Figure 3 illustrates the percentage of fuel premixed ratio at different engine load at fixed engine speed 1200 RPM and different injection pressure when the fuel system temperature kept constant at $25^{\circ} \mathrm{C}$. As clear in Figure 3 that by increasing the injection pressure the fuel premixed ratio increases at both low load conditions and high load conditions. While, the effect of fuel premixed ratio increment is more pronounced between $P_{i n j}$ is between 75 and 200 bars. Furthermore, for the same engine load by increasing the pressure between the mentioned values the fuel premixed ratio is increased rapidly. Never less, increasing the injection pressure more than 200 bars will add more loads on the tested engine pump without remarkable improvement in the overall fuel premixed ratio for the whole system. In low load conditions, the amount of fuel injected is very small in each cycle, while, in high load conditions, the amount of fuel injected is larger. At the same injection pressure, if the amount of the fuel injected increases, the cone angle, penetration of the spray, the number of droplets, and the droplet diameter will increase. The result matches well the results we obtained from our simulation work presented before in the previous publication [24]. By increasing the injection pressure slightly the amount of vapor present in the system and the fuel premixed ratio will take to increase until reach a certain value then it will keep on an almost constant manner.

To retain our results and provide more details of the operating range for the system optimal injection pressure and injection temperature we will select the values of injection pressures between 75 and 200 bar to study the effect of varying system temperature on the fuel premixed ratio at fixed engine speed 1200 RPM. As can be seen in Figure 4 we can conclude from the results that at the same load conditions, intake temperature and injection pressure are important factors for FPR. Moreover the increasing value of the fuel premixed ratio in our case did not increase randomly. The optimal operating conditions for our case will locate in the pressure range between 75 and 200 bars, not more than these values, and the temperature effect on the fuel premixed ratio is more pronounced as the temperature increased until $225^{\circ} \mathrm{C}$.

\section{Diesel HCCI Engine Emissions}

Homogeneous Charge Compression ignition (HCCI) is an advanced combustion technology being considered

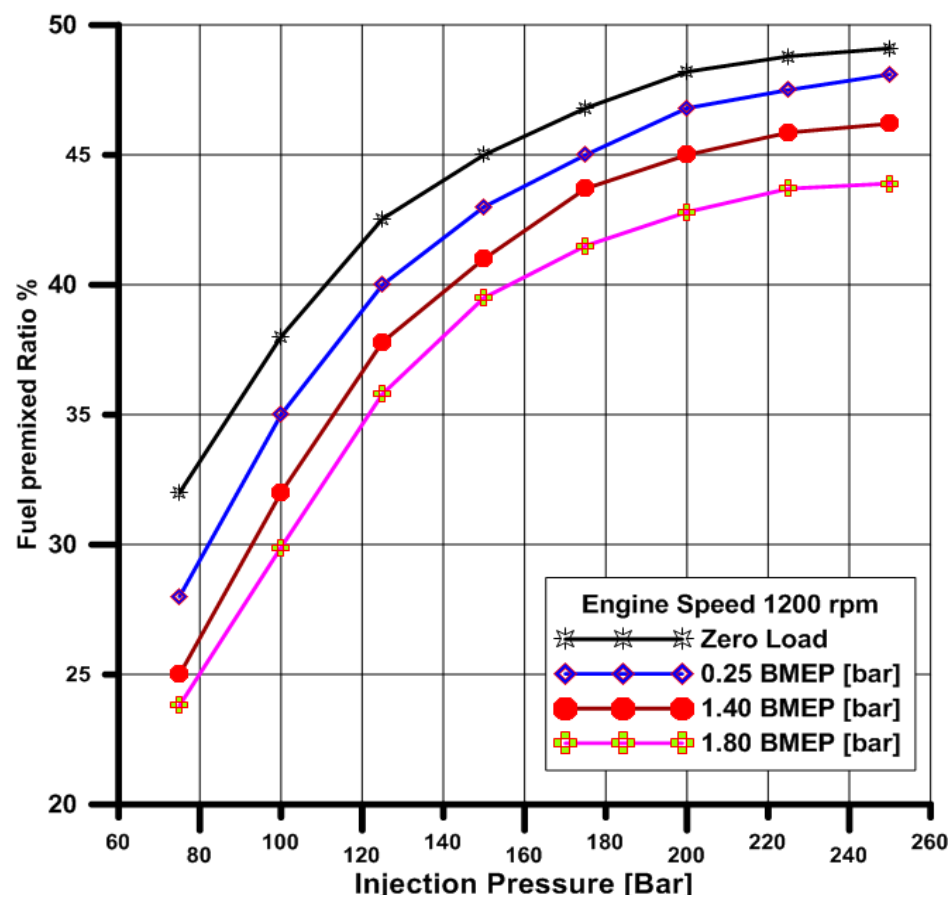

Figure 3. Fuel premixed ratio with different injection pressure at different engine loads, engine speed $1200 \mathrm{RPM}$, and $25^{\circ} \mathrm{C}$ fuel system temperature. 


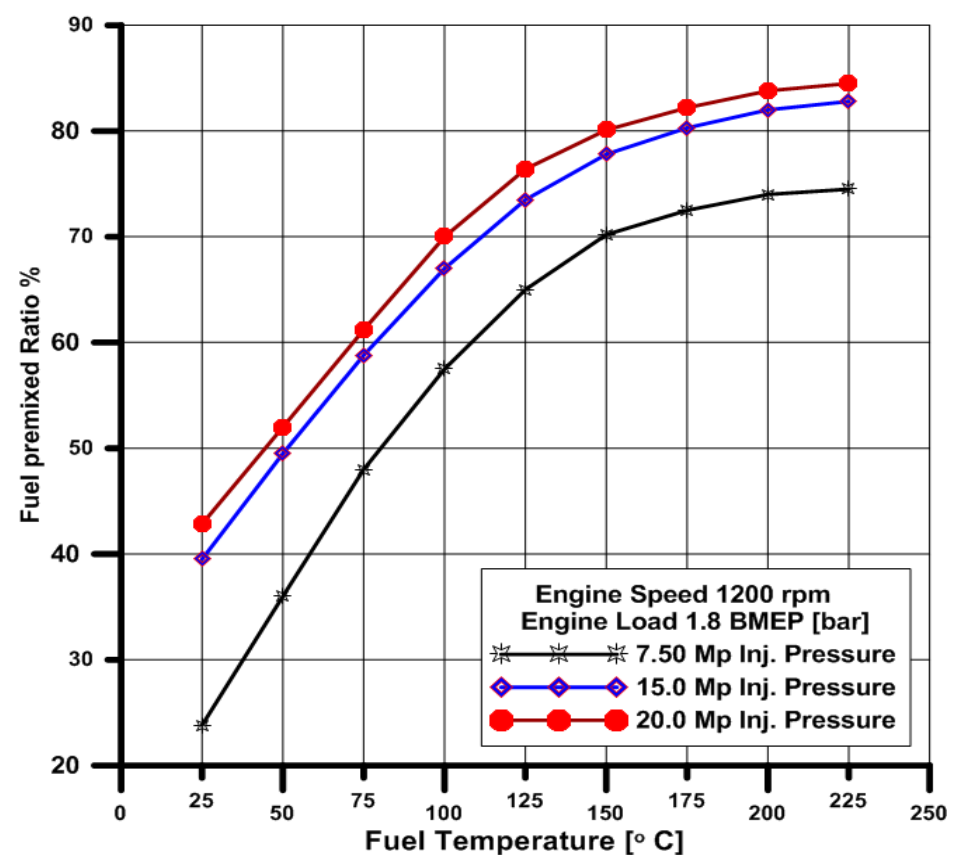

Figure 4. Fuel premixed ratio at different injection pressure and 1200 RPM with different fuel injection temperature (fuel system temperatures).

for use in internal combustion (IC) engines to improve fuel economy and reduce $\mathrm{NO}_{\mathrm{x}}$ and soot emissions. In the $\mathrm{CI}$ engine, the $\mathrm{NO}_{\mathrm{x}}$ is formed in very hot zones closer to stoichiometric conditions and soot is formed in the fuel rich regions. The in-cylinder average air/fuel ratio is globally always lean, but locally the combustion process is not. This means that there is a large potential to reduce emissions of $\mathrm{NO}_{\mathrm{x}}$ and $\mathrm{PM}$ by simply mixing fuel and air before combustion take place. In the present study, a homogeneous mixture of the diesel fuel and air was formed by using our technique for the vaporization of diesel in the intake manifold (external mixture formation) to achieve HCCI combustion. In HCCI mode, the shorter combustion duration and lower combustion temperature lead to lower $\mathrm{NO}_{\mathrm{x}}$ and soot emissions, but higher unburned hydrocarbon (HC) and carbon monoxide (CO) emissions compared with standard diesel engines. The experimental results show that the $\mathrm{NO}_{\mathrm{x}}$ concentration in the exhaust pipe does not exceeding $10 \mathrm{ppm}$ in all of our engine conditions. The power output of the HCCI engine is also limited since the combustion can become unstable and knock-like cylinder pressure oscillations occur as the mixture approaches stoichiometric.

From the previous section we already performed an optimization for the range of operating injection pressure and temperature. The analysis of the engine emissions will be performed in the same pre-defined range in order to fasten our results upon the engine operating range. We will study the effect of our proposed technique on the emissions of the HCCI engine at different operating conditions of fuel temperature and injection pressure with different engine loads. Herein we aim to obtain a desired operating condition, in terms of different engine load condition and several options of the fuel injection temperature and pressure are available from our experimental results and the emission analysis performed.

\section{1. $\mathrm{HCCI}$ Engine $\mathrm{CO}_{2}$ Emissions}

Figure 5 shows oxides of Carbon $\left(\mathrm{CO}_{2}\right)$ emissions as a function of injection pressure and temperature for various engine loads as well as a constant speed of engine 1200 RPM. $\mathrm{CO}_{2}$ emissions were almost independent of the injection pressure as it is shown a constant manner of variation with different injection pressure. It exponentially increased and almost stayed constant between $0.8 \%$, and $2.5 \%$ (percentage by volume from exhaust gas emission) as the pressure increased. It is obvious that at high engine loads the presence of $\mathrm{CO}_{2}$ is more pronounced especially as the injection pressure increased to the range of 150 to 200 bars which means the combustion of fuel is better at higher injection pressure. However, with a fixed engine load 1.8 BMEP and 1200 RPM the increasing of the $\mathrm{CO}_{2}$ emissions is slightly different in high injection pressure conditions 150 bars, and 200 
bars. Although 75 bars were the lowest tested pressure, but the rate of $\mathrm{CO}_{2}$ formation at that pressure with increasing temperature is very highly increased when the temperature located between $25^{\circ} \mathrm{C}$ until $150^{\circ} \mathrm{C}$ while it stay constant from $150^{\circ} \mathrm{C}$ to $225^{\circ} \mathrm{C}$. This result indicates that $\mathrm{CO}_{2}$ emissions are more a function of the engine load and the diesel fuel injection temperature rather than engine speed or injection pressure in an HCCI engine.

\subsection{HCCI Engine HC Emissions}

In Figure 6, hydrocarbon HC emissions increased in a 2nd order polynomial manner with injection pressure variation. As the engine speed is constant and the injection pressure increased then the amount of HC emission will be decreased. While, HC emission increased comparatively with increased engine load. Figure 6 also shows hydrocarbon (HC) emission as a function of fuel injection temperature for various injection pressure at fixed engine speed and load, 1200 RPM, and 1.8 BMEP, respectively. HC was about 150 - 130 ppm and it decreased in a $2^{\text {nd }}$ order polynomial manner when the injection temperature increased with the same injection pressure. Higher fuel injection pressure showed faster decrease in HC. The concentrations of HC represent the importance of fuel vaporization in the HCCI engine combustion improvement. The results indicated that raising the fuel temperature and the injection pressure, especially in the high load case will enhance the combustion in the engine as it reduces the HC presence in the engine emissions. It can be observed that the engine operated with diesel vapor-air mixture exhibits a significant reduction in $\mathrm{HC}$ at all loads. However, mixture is available inside the cylinder as a homogeneous mixture is completely supplied to the engine. Hence there is an absolutely free combustion from the liquid fraction of fuel pockets with increased temperature and pressure for the same load and speed.

\subsection{HCCI Engine CO Emissions}

In Figure 7, it is clear that by increasing the injection pressure at the same engine load the CO emission decreased dramatically. Furthermore, the decreasing manner of the CO is almost constant in all cases examined. Also, the tested highest engine load was recorded the lowest values of CO emissions for the same value of injection pressure and engine speed. However, increasing the fuel temperature at the same injection pressure with the fixed engine load will decrease the amount of $\mathrm{CO}$ emissions formed as a result of the combustion process. For the same examined fuel system injection temperature the highest pressure applied is recorded the lowest CO emissions in the test cases. It is widely known that, the $\mathrm{CO}$ emissions are results of hydrocarbon incomplete combustion. CO emissions are one of the major setbacks of HCCI engine. One major factor, which contributes to higher CO emissions, is low temperature combustion due to lean HCCI engine mixture. As a conclusion from these results, by increasing the injection pressure and injection temperature the mixture preparation for the HCCI engine will be enhanced. The investigation has shown that a diesel engine can run on a homogeneous fuel/air mixture that is generated externally in a fuel vaporizer chamber. The emissions results are very good
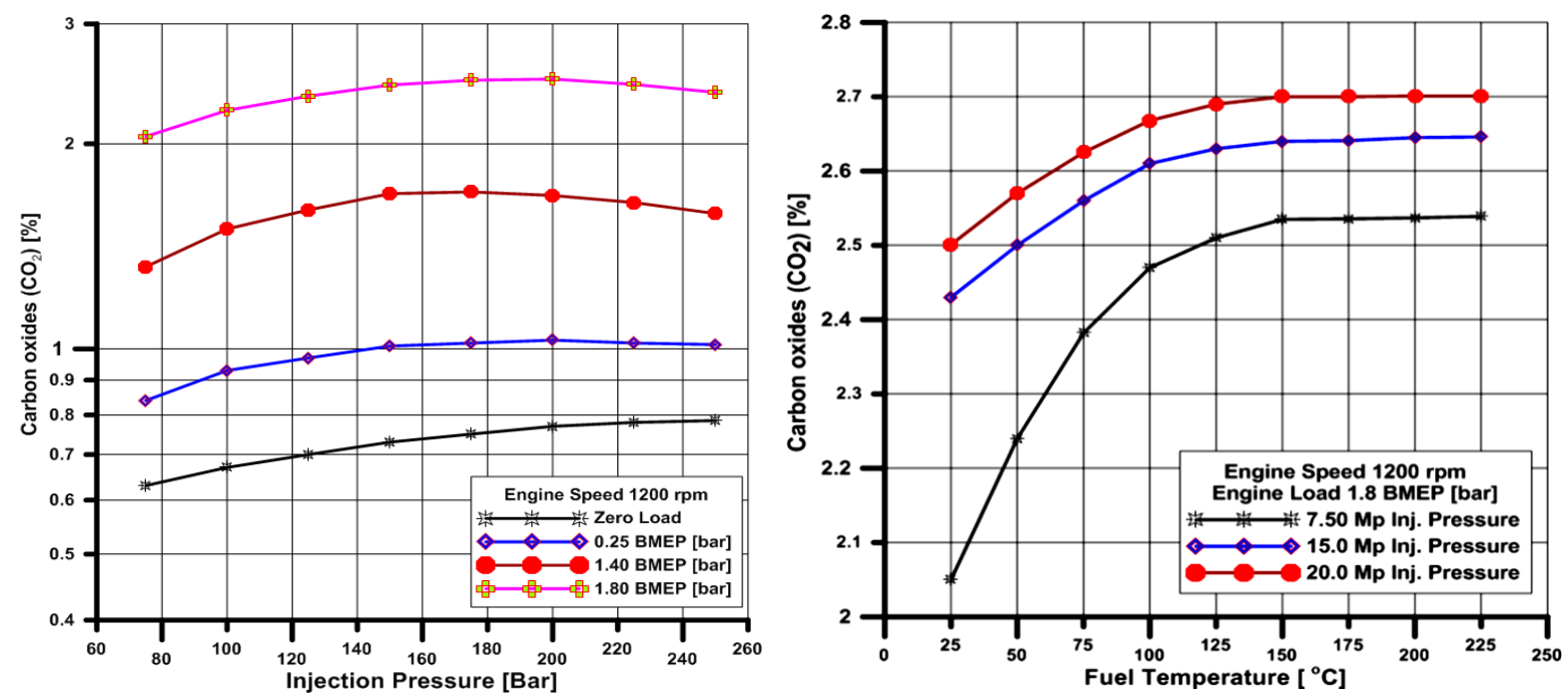

Figure 5. Variation of $\mathrm{CO}_{2}$ emission as a function of fuel temperature and injection pressure at engine speed $1200 \mathrm{RPM}$ and different load condition. 

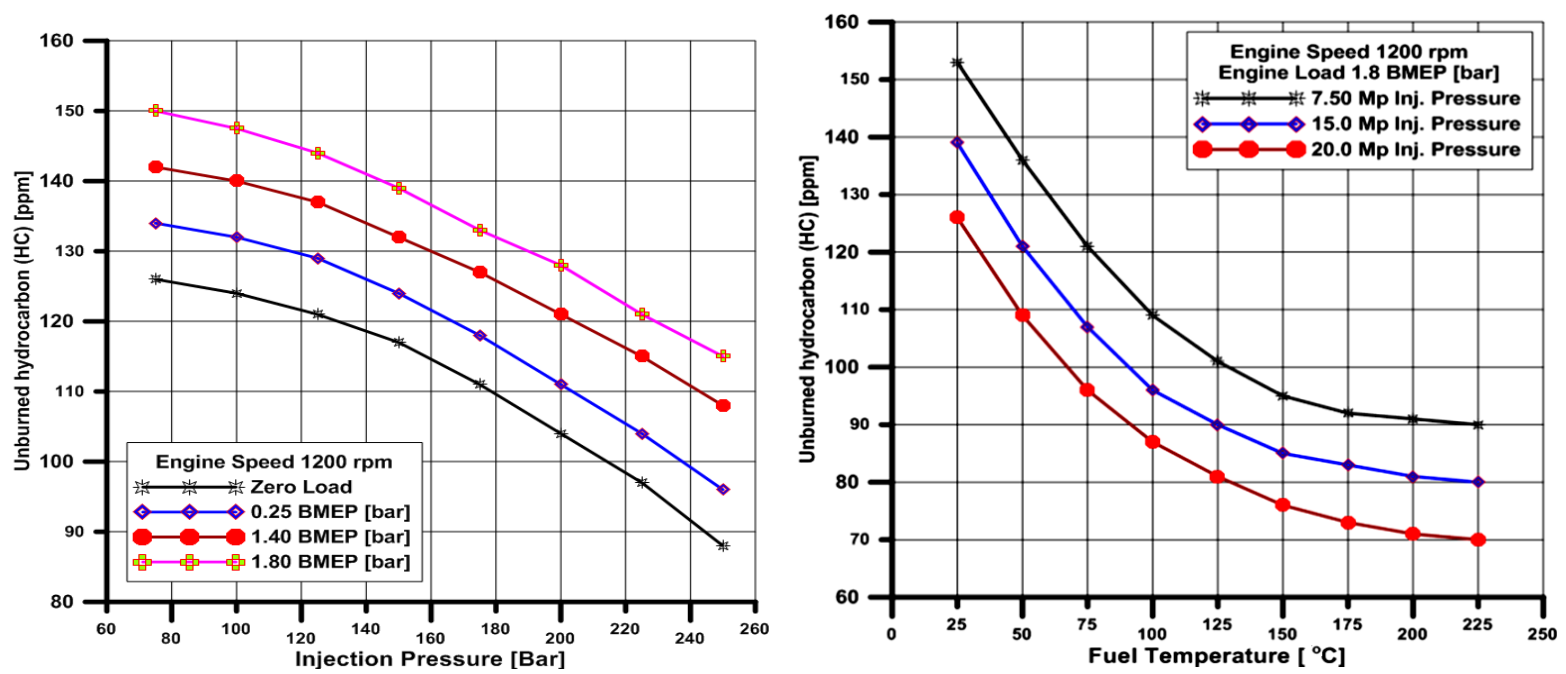

Figure 6. Variation of HC emission as a function of fuel temperature and injection pressure at engine speed 1200 RPM and different load condition.
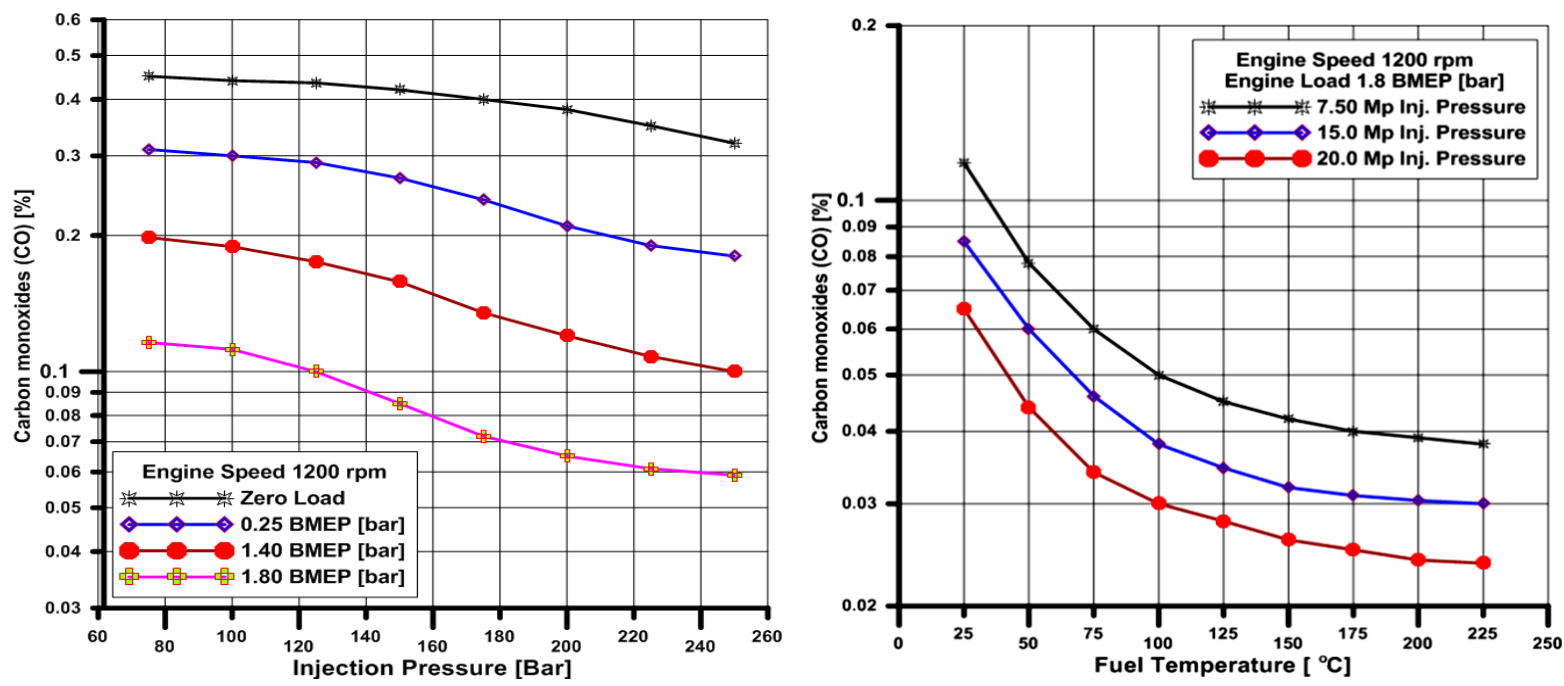

Figure 7. Variation of CO emission as a function of fuel temperature and injection pressure at engine speed 1200 RPM and different load condition.

describing the exact chart for the engine working map. As a remarkable engine results show, there is almost zero NOX emission have recorded during the operation of our achieved method of the diesel HCCI engine.

\section{Monitoring of Diesel HCCI Engine Combustion}

The present section presents some of the different cases and operating conditions for comparing engine performance data variations in order to monitor the engine performance and operation. The following engine data analysis will be introduced in order to be as a guide or an operating map for the future researchers working on this issue. Thus, the engine raw data available about the single mode pure diesel HCCI engine is very little, or in another word there are no data for the operating chart of diesel HCCI engines. The engine experimental data are collected simultaneously with the recording of engine performance data at an instant. It has noted that the characteristics of the diesel HCCI engine operating conditions are reflected in the experimental data analysis. Conversely, this means that information about the engine performance variables can provide an insight into the engine conditions and confirm whether these are normal or otherwise the engine operation is not going smoothly. Cylinder pressure and engine performance analysis procedures detect abnormal combustion or engine emissions 
conditions providing early warning of developing problems whether from incorrect settings or component malfunction. The diagnostic procedures for studying engine operating characteristics and engine performance have developed and calculated by aid of a code achieved to calculate the most important features of engine operation at different conditions. By the interpretation of the information collected developing faults can be identified well before they may be visible through the performance data or physical inspection. Evaluation of information from the analysis also allows recommendations for adjustments to diesel fuel evaporation, and engine settings, and for planning of an overhaul of injectors and engine units.

In-cylinder pressure data analysis is the most effective way to analyze the engine combustion behavior because in-cylinder pressure history directly influences the power output, combustion characteristics and emissions from an engine. Figures 8 show the measured cylinder pressure data versus crank angle at 200 bars injection pressure, fuel system temperature $150^{\circ} \mathrm{C}$, and $1200 \mathrm{RPM}$, at different engine load. This figure clearly shows the occurrence of auto-ignition (during HCCI combustion) in all studied cases. Rise in slope of pressure curve visà-vis zero load curve shows the normal start of combustion. As the mixture becomes richer, higher load conditions, start of combustion shifts towards BTDC side. It happens due to the early start of combustion during the compression stroke. For brake mean effective pressure less than 1.8 bars at no EGR, the combustion starts well before TDC. It can be noted from the representing results that the trends of the maximum pressure are more obvious increase in higher load condition. From Figure 8, it can be seen that the rate of pressure rise increases with increasing engine load which leads knock like combustion at 2.2 bars IMEP. It happens mainly because of higher rate of combustion due to charge enrichment. When charge becomes richer, it favors earlier start of combustion due to dominance of cold combustion chemistry of the diesel fuel. Higher fuel quantity (higher load condition) is responsible for higher in-cylinder pressure and earlier start of combustion.

Apparent heat release analysis is another characterization tool for HCCI combustion. It is calculated from the acquired cylinder pressure data using "zero dimensional heat release model” [25]. The HCCI heat release pattern is different from conventional combustion modes due to occurrence of the combined phenomenon of simultaneous ignition of homogeneous mixture using compression (SI and CI). Higher rate of apparent heat release in HCCI combustion creates problems in controlling the combustion rates and affects safety and structural integrity of the engine. The apparent heat release for varying the engine load without EGR effect is shown in Figure 9. The recorded results of pure diesel HCCI combustion process exhibit a two stage heat release model. The rate of heat release analysis indicates that the start of the first stage of the combustion varies little with the engine load, while the secondary stage changes significantly. In higher load conditions, the HCCI engine combustion takes place very fast with a high rate of heat release and steep pressure, which may lead to be excessive noise or even engine damage by knock like combustion.

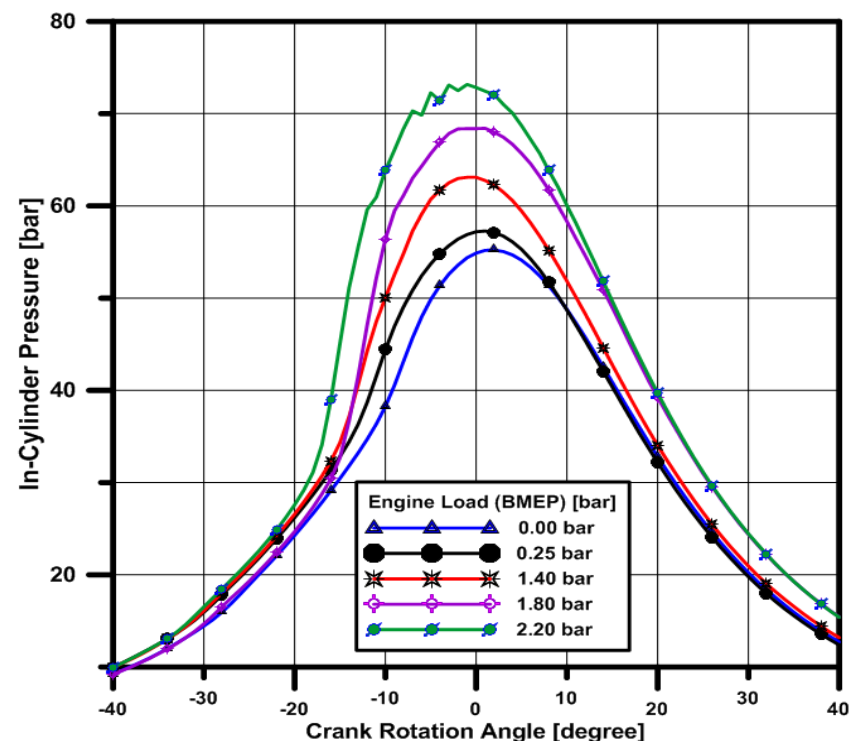

Figure 8.The in-cylinder pressure data at fixed injection pressure of 200 bars and different engine load, fuel system temperature $150^{\circ} \mathrm{C}$, engine speed 1200 RPM. 
Here, early combustion of the charge is controlled by using EGR, which retards the start of combustion significantly Figure 10. Peak cylinder pressure also decreases with increasing EGR due to reduction in rate of combustion at lower in-cylinder temperature. That observation can be obtained when comparing the recorded engine pressure data in Figure 8 with the data recorded in Figure 10 at 2.2 bars IMEP. In all three EGR conditions (20\%, 35\%, and 45\%), peak cylinder pressure occurs near TDC which shift away from TDC with increasing EGR. It happens because of delayed combustion due to mixture dilution by recirculated exhaust gas. As EGR rate increases, level of dilution also increases, increasing the delay period, which pushes the peak of the pressure curve towards the ATDC side. As the EGR rate increases, delayed combustion is observed for richer mixtures thereby affecting the HCCI combustion positively. Figure 11 shows the effect of engine load and EGR on the

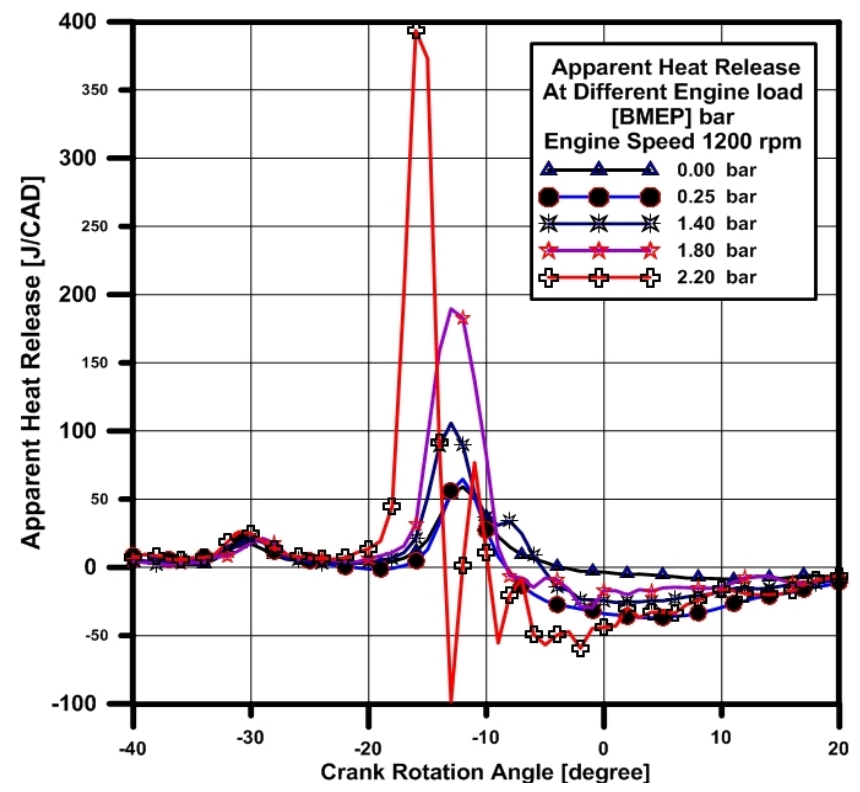

Figure 9. The in-cylinder heat energy released at different engine load and fixed injection pressure of 200 bars, fuel system temperature $150^{\circ} \mathrm{C}$, and engine speed $1200 \mathrm{RPM}$.

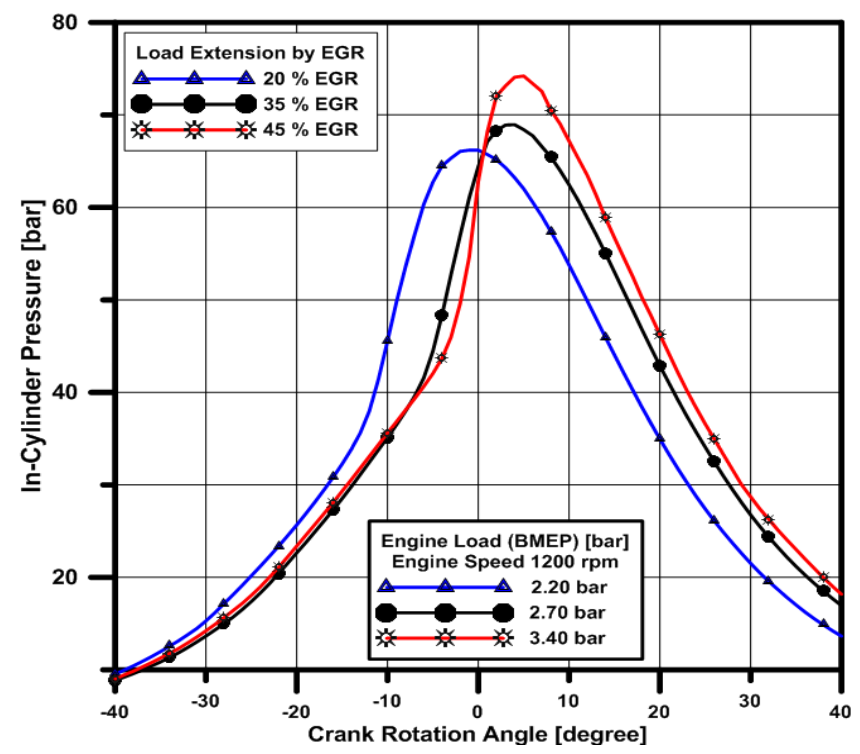

Figure 10. The in-cylinder pressure data at different engine load and EGR percentage at fixed injection pressure of 200 bars, fuel system, temperature $150^{\circ} \mathrm{C}$, and engine speed $1200 \mathrm{RPM}$. 


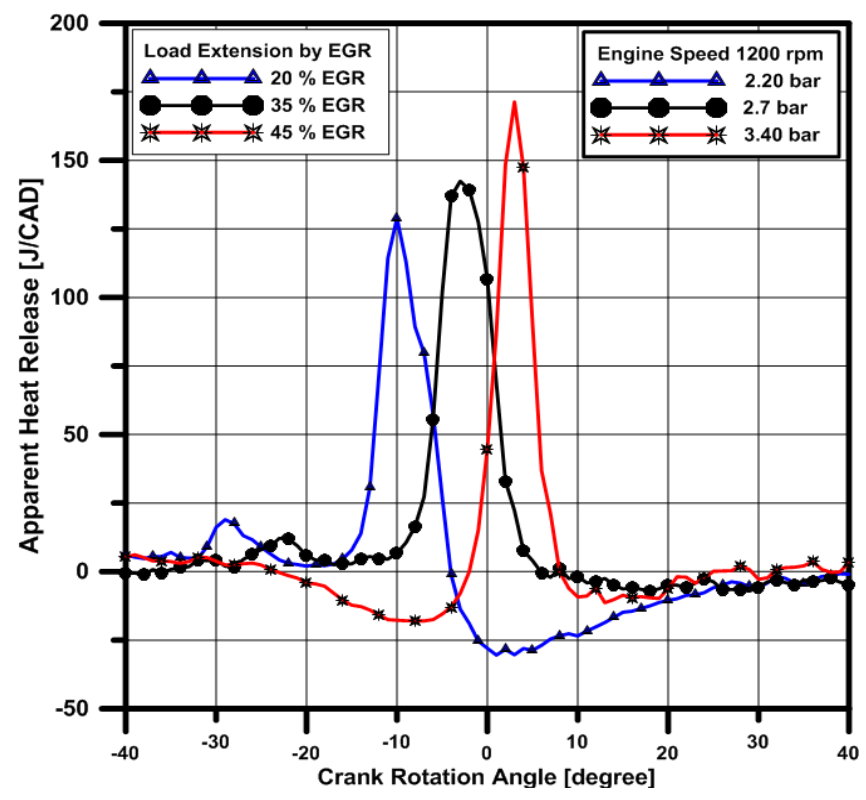

Figure 11. The in-cylinder heat released at different engine load and EGR percentage a fixed injection pressure of 200 bars, fuel system temperature $150^{\circ} \mathrm{C}$, and engine speed $1200 \mathrm{RPM}$.

apparent heat release and its crank angle position. In all three cases, the apparent heat release curve possesses two peaks, one for low temperature heat release region and the other one for high temperature heat release region. As the EGR percentage increase time delay between first and main heat release, is attributed to the "Negative Temperature Coefficient (NTC) regime”, which is located between the two heat release stages is increased.

\section{Summary and Conclusions}

In the present study, combustion and emission characteristics of a homogeneous air-diesel fuel mixture HCCI engine with external mixture formation were investigated at different engine loads and EGR percentage. The indicated results show noticeable improvement in the charge homogeneity if the external mixture preparation technique has used. The formed diesel fuel aerosol inside the diesel vaporization chamber proved successful in achieving diesel vapor by means of cavitation principal. The diesel vaporization process basically is begun inside the injector wholes by means of cavitation phenomena and continues to produce a fully vaporized diesel vapor aerosol inside a small chamber namely a diesel vaporization chamber. Fuel cavitation inside the diesel injection nozzle is mainly affected by the injection pressure and the fuel system temperature.

The engine experiments were performed at different mixture strengths to study the engine load range until the rich mixture combustion is limited by the knock-like combustion. As the engine load increased, peak in-cylinder pressure and rate of heat release increase rapidly due to higher rates of combustion and start of combustion shifts to happen before top dead center (BTDC). However, the combustion process of the diesel HCCI is highly sensitive to fuel/air homogeneity and EGR percentage. Results obtained reveal that the proposed method determines the possibility of producing a complete homogeneous fuel/air mixture, which can be applied to the diesel HCCI engine. With this method, the combustion and emission behavior were entirely optimized and the engine is capable of running in HCCI combustion mode with nearly ideal mixture preparation.

In the present investigation, a methodology for the HCCI combustion mode of the diesel aerosol/air mixtures based on the fuel cavitation inside the injector nozzle parameters (such as the injection pressure and the fuel system temperature where fuel premixed ratio, $\mathrm{NO}_{x}, \mathrm{CO}, \mathrm{CO}_{2}$, and $\mathrm{HC}$ emissions) have analyzed. Based on the engine performance and emissions characteristics the fuel injection pressure and the fuel system temperature have optimized to produce a suitable fuel premixed ratio and a perfect fuel/air mixture homogeneity at different engine operating conditions. The optimal injection pressure ranges between $150-200$ bars, while the fuel system temperature lies within $175^{\circ} \mathrm{C}-200^{\circ} \mathrm{C}$. 


\section{References}

[1] Elkelawy, M., Yu-Sheng, Z., Alm El-Din, H. and Yu, J.-Z. (2008) Challenging and Future of Homogeneous Charge Compression Ignition Engines; an Advanced and Novel Concepts Review. Journal of Power and Energy Systems, 2, 1108-1119. http://dx.doi.org/10.1299/jpes.2.1108

[2] Yao, M., Zheng, Z. and Liu, H. (2009) Progress and Recent Trends in Homogeneous Charge Compression Ignition (HCCI) Engines. Progress in Energy and Combustion Science, 35, 398-437. http://dx.doi.org/10.1016/j.pecs.2009.05.001

[3] Komninos, N.P. and Rakopoulos, C.D. (2012) Modeling HCCI Combustion of Biofuels: A Review. Renewable and Sustainable Energy Reviews, 16, 1588-1610. http://dx.doi.org/10.1016/j.rser.2011.11.026

[4] Bendu, H. and Murugan, S. (2014) Homogeneous Charge Compression Ignition (HCCI) Combustion: Mixture Preparation and Control Strategies in Diesel Engines. Renewable and Sustainable Energy Reviews, 38, 732-746. http://dx.doi.org/10.1016/j.rser.2014.07.019

[5] Elkelawy, M., Zhang, Y.-S., Alm El-Din, H. and Yu, J.-Z. (2008) Detailed Simulation of Liquid DME Homogenization and Combustion Behaviors in HCCI Engines. SAE Technical Paper 2008-01-1705. http://dx.doi.org/10.4271/2008-01-1705

[6] Ganesh, D. and Nagarajan, G. (2010) Homogeneous Charge Compression Ignition (HCCI) Combustion of Diesel Fuel with External Mixture Formation. Energy, 35, 148-157. http://dx.doi.org/10.1016/j.energy.2009.09.005

[7] Gan, S., Ng, H.K. and Pang, K.M. (2011) Homogeneous Charge Compression Ignition (HCCI) Combustion: Implementation and Effects on Pollutants in Direct Injection Diesel Engines. Applied Energy, 88, 559-567. http://dx.doi.org/10.1016/j.apenergy.2010.09.005

[8] Oliveira Panão, M.R., Moreira, A.L.N. and Durão, D.F.G. (2013) Effect of a Cross-Flow on Spray Impingement with Port Fuel Injection Systems for HCCI Engines. Fuel, 106, 249-257. http://dx.doi.org/10.1016/i.fuel.2012.11.039

[9] Yu, J.-Z., Zhang, Y.-S., Elkelawy, M. and Kui, Q. (2010) Spray and Combustion Characteristics of HCCI Engine Using DME/ Diesel Blended Fuel by Port-Injection, SAE Technical Paper 2010-01-1485. http://dx.doi.org/10.4271/2010-01-1485

[10] Singh, A.P. and Agarwal, A.K. (2012) Combustion Characteristics of Diesel HCCI Engine: An Experimental Investigation Using External Mixture Formation Technique. Applied Energy, 99, 116-125. http://dx.doi.org/10.1016/j.apenergy.2012.03.060

[11] Kim, M.Y. and Lee, C.S. (2007) Effect of a Narrow Fuel Spray Angle and a Dual Injection Configuration on the Improvement of Exhaust Emissions in a HCCI Diesel Engine. Fuel, 86, 2871-2880. http://dx.doi.org/10.1016/i.fuel.2007.03.016

[12] Ryu, J., Kim, H. and Lee, K. (2005) A Study on the Spray Structure and Evaporation Characteristic of Common Rail Type High Pressure Injector in Homogeneous Charge Compression Ignition Engine. Fuel, 84, 2341-2350. http://dx.doi.org/10.1016/j.fuel.2005.03.032

[13] Elkelawy, M., Zhang, Y.-S., Alm El-Din, H., Yu, J.-Z., El Zahaby, A., El Shenawy, E., et al. (2009) Experimental Study on Flash Boiling and Micro-Explosion of Emulsified Diesel Fuel Spray Droplets by Shadowgraph Technology. Transactions of CSICE, 27, 306-308.

[14] Leng, X., Feng, L., Tian, J., Du, B., Long, W. and Tian, H. (2010) A Study of the Mixture Formation Process for a Third-Generation Conical Spray Applied in HCCI Diesel Combustion. Fuel, 89, 392-398. http://dx.doi.org/10.1016/j.fuel.2009.08.021

[15] Turkcan, A., Ozsezen, A.N. and Canakci, M. (2014) Experimental Investigation of the Effects of Different Injection Parameters on a Direct Injection HCCI Engine Fueled with Alcohol-Gasoline Fuel Blends. Fuel Processing Technology, 126, 487-496. http://dx.doi.org/10.1016/j.fuproc.2014.05.023

[16] Coskun, G., Soyhan, H.S., Demir, U., Turkcan, A., Ozsezen, A.N. and Canakci, M. (2014) Influences of Second Injection Variations on Combustion and Emissions of an HCCI-DI Engine: Experiments and CFD Modelling. Fuel, 136, 287-294. http://dx.doi.org/10.1016/j.fuel.2014.07.042

[17] Wu, Z., Bao, T., Zhang, Q., Yan, S. and Deng, J. (2014) Experimental Study on Spray Combustion Characteristics of Gasoline-Diesel Blended Fuel in a Controllable Active Thermo-Atmosphere. Fuel, 135, 374-379. http://dx.doi.org/10.1016/j.fuel.2014.06.073

[18] Hairuddin, A.A., Yusaf, T. and Wandel, A.P. (2014) A Review of Hydrogen and Natural Gas Addition in Diesel HCCI Engines. Renewable and Sustainable Energy Reviews, 32, 739-761. http://dx.doi.org/10.1016/j.rser.2014.01.018

[19] Deshmukh, B.S., Babu, M.K.G., Kumar, M.N., Das, L.M. and Aghav, Y. (2012) Simulation Approach for Quantifying the Homogeneity of In-Cylinder Mixture Formation for Port Injected Diesel Fuel for PCCI/HCCI. International Journal of Scientific \& Engineering Research, 3. 
[20] Spindt, R.S. (1965) Air-Fuel Ratios from Exhaust Gas Analysis. SAE Technical Paper 650507. http://dx.doi.org/10.4271/650507

[21] Bresenham, D., Reisel, J. and Neusen, K. (1998) Spindt Air-Fuel Ratio Method Generalization for Oxygenated Fuels. SAE Technical Paper 982054. http://dx.doi.org/10.4271/982054

[22] Lynch, D. and Smith, W.J. (1997) Comparison of AFR Calculation Methods Using Gas Analysis and Mass Flow Measurement. SAE Technical Paper 971013. http://dx.doi.org/10.4271/971013

[23] El-Din, H.A., Zhang, Y.S. and Elkelawy, M. (2012) A Computational Study of Cavitation Model Validity Using a New Quantitative Criterion. Chinese Physics Letters, 29, Article ID: 064703. http://dx.doi.org/10.1088/0256-307X/29/6/064703

[24] Bastawissi, H. and Elkelawy, M. (2012) Computational Evaluation of Nozzle Flow and Cavitation Characteristics in a Diesel Injector. SAE Technical Paper 2012-01-1652. http://dx.doi.org/10.4271/2012-01-1652

[25] Heywood, J. (1988) Internal Combustion Engine Fundamentals. McGraw-Hill Book Company, New York. 
Scientific Research Publishing (SCIRP) is one of the largest Open Access journal publishers. It is currently publishing more than 200 open access, online, peer-reviewed journals covering a wide range of academic disciplines. SCIRP serves the worldwide academic communities and contributes to the progress and application of science with its publication.

Other selected journals from SCIRP are listed as below. Submit your manuscript to us via either submit@scirp.org or Online Submission Portal.
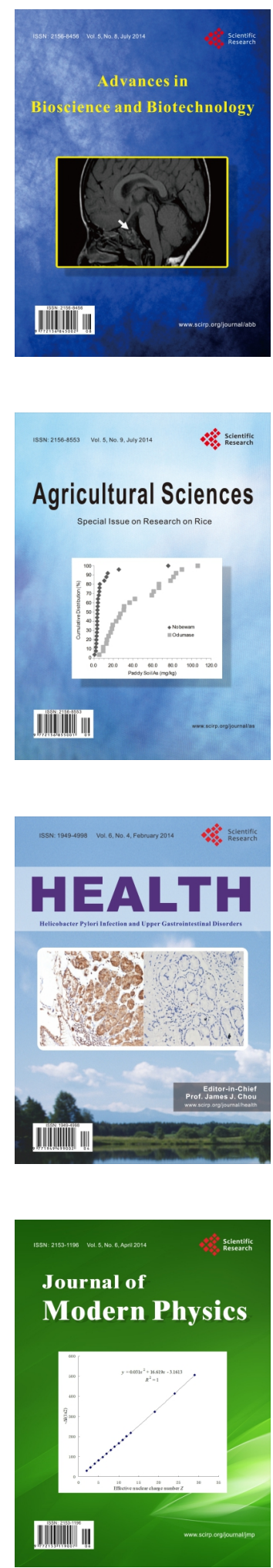
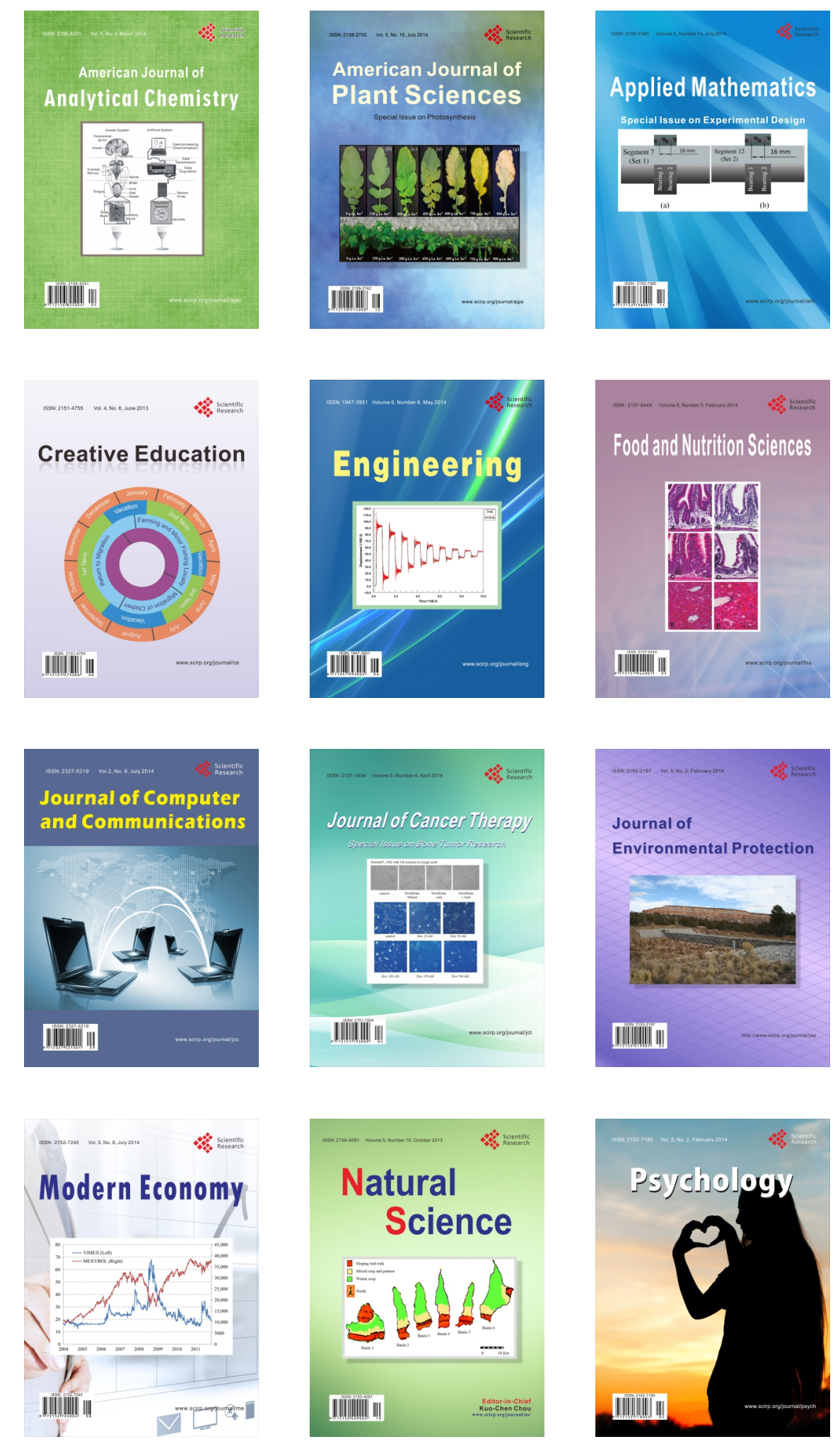